\title{
Research on Ideological and Political Education of College Students from the Perspective of System Theory
}

\author{
Yu Zhang \\ (School of Marxism, Tongji University, Shanghai,200092)
}

\begin{abstract}
General Secretary Xi Jinping pointed out that college education should always focus on what kind of people to cultivate and for whom to develop. Especially under the background of the new era, the state vigorously supports the cause of ideological education. It regards the establishment of morality as the top priority of ideological and political education in colleges and universities. The essence of accepting theory is system theory, and it has an internal agreement with the running system of ideological and political education of college students. That is, it has the consistency of constituent elements and the similarity of operation process. In this paper, the operating process of the receiving system is divided into six stages: driving, regulating, guiding, selecting, performing, and processing and the factors are analyzed by combining it with the subject, object, ring, and interface.
\end{abstract}

Keywords: reception theory; college students; ideological and political education

DOI : $10.36012 /$ fhe. v2i2. 2764

\section{Related Interpretation of Reception Theory and System Theory}

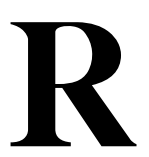

eception theory is a teacher of western hermeneutics. German academic Hans Robert Jauss (1921 - 1997) put forward many new concepts of reception theory. The key to the reception theory is to look forward to the vision. Hans Robert Jauss believes that expectation vision is related to readers reading experience, self - consciousness, value preference, class status, and other factors. There is, and only with the vision of expectation, the information accepted by the reader has value. A second important concept in Israel Broussard reception theory is summoning structure. He believes that no work can be ultimately a complete structure, which contains uncertain gaps. When the reader reads this work, it has different and changing expectations about the content, the coherence of the plot, the presentation of the language and so on. While there is an expectation, try to fill the blank of the text with an imaginary plot, language, content, etc., that is, a thousand people have a thousand ways of understanding. The third important concept in Israel Broussard's reception theory is "implicit reader". Israel Broussard thinks that implicit reader theory emphasizes the important role of the reader to text and world.

There are many pieces of research on system theory in China, including social system theory, engineering system theory, reception system theory, and so on. Gao Jingwen believes that social system theory emphasizes the particularity of social system and describes the characteristics of social system qualitatively from the macro whole. The social system theory in modern system science emphasizes the commonality between the social system and natural system. It quantitatively de- 
scribes the characteristics of the social system from a certain side or level. ${ }^{[2]}$ Liu Gang believes that the engineering system theory is a cross - cutting subject based on the principles and laws of system science as the guiding ideology and theoretical basis at the top level and supported by technical disciplines such as system engineering and artificial system science, supplemented by mathematical tools such as fuzzy mathematics and fractal dimension. ${ }^{[3]}$ Liu Xianyi puts forward that the receiving system is a micro-software system that is attached to the structure of the main brain function and is composed of multi- level psychological and consciousness elements to process and integrate information and form human concept and cognition. Corresponding to the three functional structures of the brain, three interrelated functional subsystems are formed. This paper mainly adopts the reception system theory proposed by Liu Xianyi, which includes primarily three subsystems. These three subsystems interact together to form the reception schema. First, the driving regulation system consists of different levels of needs, motivation, and other psychological factors, such as emotion, will, interest, and so on. It can activate the arousal structure of the brain nerve or close it. Thus causing the beginning and end of the reception activity and then improving or reducing the reception efficiency. Second, the guiding selection system is composed of the original concept and stereotype psychology, and under the premise of interacting with the motivation system, the information entering the brain is judged and screened. To solve the problem of receiving activities and how to choose and deal with objects. Third, the operation and processing system regards the way of thinking and skills as tools, regards knowledge and experience as raw materials, and regards the process of receiving information and processing and maintaining the cognitive structure of the brain nerve as the carrier of its operation and operation, which in turn stimulates its ability to deal with and understand. The three subsystems operate independent- ly and act on each other in different links of the reception process to form the reception kinetic energy of the subject and jointly affect the direction and effect of the reception activity. ${ }^{[4]}$

\section{Reception of System Theory and Ideological and Political Education}

Ideological and political education mainly includes four elements : educational subject, educational object, educational medium and educational environment. The ideological and political education of college students can be defined as the scientific design of the ideological and political education activities of college students by educators. According to the corresponding purpose and content, methods to strengthen ideological and political education, and always follow the relevant characteristics of college students' thought, psychology and behavior, constantly improve their quality, integrate and optimize the educational environment, so that students can form a moral quality that meets the social requirements. ${ }^{[5]}$ The reason why accepting system theory can be applied to the study of the effectiveness of ideological and political education is that accepting system theory is compatible with ideological and political education. The agreement between the two is mainly reflected in the consistency of the constituent elements and the similarity of the running process.

\section{1 Consistency of Constituent Elements}

The constituent elements of receiving system include receiving subject, accepting object, accepting medium and accepting ring. Ideological and political education is also composed of four elements : educational subject, educational object, educational medium, and educational environment. It is worth noting that the subject of reception is equal to the object of education, and the object of reception is consistent with the subject of education. Therefore, it is feasible to integrate the reception system theory into the effectiveness study.

\section{2 The Running Process Is Similar}

The operation of the receiving system is formed by the interaction of three subsystems. Here, the 
three subsystems can be decomposed into a continuous process, that is, drive-regulation - orientation - selection - operation - processing. This is similar to the process of ideological and political education from externalization to internalization and is consistent in essence. The similarity of operation process provides theoretical support for the research of this topic.

\section{The Dilemma of College Students' Ideolog- ical and Political Education}

Although the ideological and political education of college students has achieved certain results, it also faces many difficulties. The dilemma can be explained by the contradiction between the need for ideological and political education and the lack of motivation, the conflict between the rich theory and the lack of practice, the impact of the coexistence of monism and pluralism.

\section{1 The Need for Exuberance and Weak Motivation}

In the ideological and political education activities for college students, the purpose of ideological and political education is to effectively influence the $i^{-}$ deological concept, political viewpoint, and moral quality of college students. Their thinking height is in line with the requirements of the development of the socialist cause. It also faces many difficulties in the process of reception. The first is the contradiction between the need for exuberance and the lack of motivation. Ideological and political education runs through the teaching activities, assess and judge the reception effect of college students in many ways. As one of the important conditions for evaluating awards, college students need to receive ideological and political education to make themselves conform to the social evaluation standards, so the need for exuberant meaning is self - evident. In this process, there is also the problem of insufficient motivation. As the subject of reception, college students cannot correctly realize the importance of receiving ideological and political education at every stage. They also lack long - term understanding and correct cognition on treating the boring theory of serious content and lack of vivid breath correctly. The contradiction between the need for exuberance and the lack of motivation also reflects that the subject does not correctly recognize its subjective status, which is also an indirect embodiment of the lack of preparation of the subject. To some extent, this embodiment also means that the influence and infection of educators on the subject do not achieve the desired effect, thus interfering with the effectiveness of ideological and political education. In a word, the cause of this contradiction seems to be most closely related to the stage characteristics of the general psychological immaturity of college students as the subject of reception. Still, it is also closely related to the benign and two - way interaction between the educator and the subject of reception. Therefore, it is necessary and urgent to construct a new type of two - way interaction, a democratic and equal teacher - student relationship. The enlightenment brought by the drive regulation system in the reception theory is that given the problem of the effectiveness of ideological and political education of college students, we should take the motivation of different levels of the subject as the premise and take the influence and infection of the subject as the foothold.

\section{2 Disorder of Interest Dominance and Misalign- ment of Quality}

College students often tend to pre - judge the effectiveness of ideological and political education according to the existing psychological stereotype and concept structure, which has subjective assumptions. Besides, many theoretical systems are incomplete, and many viewpoints and theories are still controversial in the theoretical circle. Therefore, the necessity and importance of this subject are inevitably questioned. College students have only a superficial understanding of the effectiveness of ideological and political education and its pre-achieving goal, so their understanding of ideological and political education is one - sided. Nowadays, the ideological and political education of college students focuses on all- round develop- 
ment and strives to achieve the all- round development of morality, intelligence, body, beauty, and labor. Although the goal design pays attention to the development of quality, it neglects the requirement of quality in practical operation and has a strong color of profit - seeking. The achievement of the goal of ideological and political education of college students is linked to the material interests and vulgarizes the training goal and means, which to a certain extent makes the way and method of ideological and political education of college students deviate to a certain extent. The deviation of methods and the vulgarization of means and objectives make the reception effect of ideological and political education of college students greatly reduced, and also affect the effectiveness of ideological and political education of college students. The ultimate purpose of theoretical indoctrination is to make the subject accept the advanced theory and realize the promotion of personal ideological and political consciousness and make it conform to the requirements of social development. However, due to the limitation of subjective and objective conditions, the materialized phenomenon affects the effectiveness of ideological and political education of college students. The guidance selection system enlightens educators to pay attention to the original cognitive structure and thinking mode of the subject and to carry out targeted ideological and political education. The recipient should also be good at introspection and consciously eliminate the stubborn disease of ideological and political education in the original concept.

\section{3 The Conflict between Theoretical Enrichment and Practice Scarcity}

In the process of ideological and political education for college students, ideological and political education activities themselves call for the active and active participation of college students. Many scholars in academic circles, such as Zhang Yaocan and Professor Shen Zhuanghai, have deep attainments in the theory of ideological and political education, which makes corresponding theoretical re- serve for college students' ideological and political education. Nowadays, the theory of ideological and political education is greatly developed, but the concrete implementation is very few in practice. The practice experience is vague and has not been greatly developed because of the limitation of subjective and objective conditions. The ideological and political education of college students is still based on classroom theory indoctrination, and the development of social practice activities has not been paid enough attention. Also, when educators focus on the teaching of ideological and political education theory, they often ignore the exploration of ideological and political education practice and the guidance of college students' practice. At present, the establishment of many ideological and political education practices bases, on the one hand, shows that all walks of life attach importance to the ideological and political education practice of college students, on the other hand, it also gives rise to new practical problems. For example, how to ensure that the relevant social practice activities of college students' ideological and political education will not evolve into vulgar activities with the ultimate goal of obtaining credit alone, whether the effectiveness of college students' ideological and political education practice is only measured by a single report as the evaluation standard, and how to avoid college students treating ideological and political education practice activities with the mentality of "completing tasks" and so on. Therefore, one of the problems in the ideological and political education of college students is the rich theoretical guidance but the lack of practical operation. The lack of practical operation makes college students unable to achieve the real unity of knowledge and practice in ideological and political education activities, which greatly affects the effectiveness of ideological and political education of college students. At present, most of the ideological and political education activities focus on highlighting the dominant position of educators and selectively ignoring the subjective initiative of the subject. The practice 
is an effective method to arouse the enthusiasm of the subject and can effectively present the effect of the teacher's theory in the real world through the concrete operation of the recipient. To some extent, the interaction of social relations constitutes a complete reception activity. The achievement of the effectiveness of ideological and political education of college students must be realized by the subject internalizing the experience gained from long - term practical activities into the deep knowledge and moral structure of the subject.

\section{4 The Impact of the Coexistence of Univariate}

\section{Dominance and Pluralism}

Since the reform and opening up, our country has always adhered to the concept of inclusive development, allowed foreign multiculturalism to be introduced into China, and held a respectful and inclusive attitude towards the culture of different nationalities and races. Therefore, the cultural situation of our country presents the characteristics of the one-dimensional leading and pluralistic coexistence. Under this characteristic, college students still retain the right of freedom of belief on the premise of deep understanding of the unity leading of Marxist thought. However, the coexistence of pluralism and the development of the leading thought of unity have brought some troubles to college students' ideological and political education. Some pluralistic ideas are too radical or conservative, although they are reasonable but incompatible with China's basic national conditions. These ideas can be introduced as a kind of thought in a learning attitude but cannot conflict with the onedimensional leading idea. ${ }^{[6]}$ There is no denying the necessity of a top - down theoretical indoctrination model in the current social environment. One of the most important products in accepting activities is that people perceive the objective world by stereotyping objective things. To avoid creating dilemmas or psychological conflicts for themselves, they often choose only information that is consistent with personal beliefs and stereotypes and can strengthen it. Therefore, the best way to overcome the limitation of external communication is to instill a subtle theoretical indoctrination into the group of college students so that they can identify with Marxist theory from inside out and realize that monism and pluralism are cultural concepts in line with China's current national conditions. To improve the effectiveness of college students' ideological and political education, it can reduce the resistance of college students to theoretical indoctrination and enhance their enthusiasm to accept the Marxist theory and ideological and political education.

\section{Analysis on Influencing Factors of College Students' Ideological and Political Education from the Perspective of System Theory}

From the point of view of accepting system theory, college students' ideological and political education is facing many difficulties. To improve the predic ${ }^{-}$ ament effectively, we must analyze the influencing factors accordingly. It can be analyzed from driving, adjusting, guiding, selecting, deducing, processing, and so on.

\section{1 The Factors Influencing the Reception of the} Subject in Stages of the System

4.1. 1 Reception Subject Drive. In the Oxford Dictionary, the internal driving force is defined as the internal state of an organism aroused by internal stimuli and directed to a certain goal. ${ }^{[7]}$ In this paper, the internal driving force of college students can be discussed from three aspects: cognition, $\mathrm{e}^{-}$ motion, and will. First of all, college students do not know the importance of ideological and political education. Because college students' learning and understanding of this theory is still incomplete, they cannot perceive its importance from inside to outside. The influence of stereotype psychology is only treated as a tool of ideological control. In their cognition, the theory is only floating in the air and has no practical quality. Secondly, the emotional factors of college students also influence their internal driving force imperceptibly. Contemporary college students are more and more pursuit of personality and good at showing them- 
selves, with more distinct personality characteristics, at the same time, their emotions such as anger and sadness are more obvious. Its evaluation of some things is more inclined to judge from selfposition and according to self - love and evil. In college students' ideological and political education, because of the lack of original cognition, college students cannot accept the theory and experience instilled from the outside. On the contrary, it will lead to reverse psychology, which directly affects the reception of ideological and political education. Thirdly, the willpower of college students also has an impact on their reception. College students are in the youth period and are in the critical transition period from school to society. In this period, the outlook on life and values of college students are in the stage of remodeling, and so their ideas are easily influenced by external things. At this stage, the willpower of college students is weak and more vulnerable to the corrosion of decadent and extravagant ideas and form wrong values to give up the persistence of right ideas. So it is absolutely necessary to carry out continued ideological and political education for college students.

The external driving force of college students is mainly influenced by the need of ideological and political education from family, school, and society, which is embodied in the construction of family virtue, social morality, professional ethics, and personal virtue. First of all, the need for college students to receive ideological and political education at the family level is insufficient. Family is the earliest place to carry out ideological and political education for college students. At present, college students spend most of their time in school. The frequency of returning home gradually decreases, so family's influence on their ideological and political education is becoming less and less. Secondly, the school atmosphere is relaxed and free, allowing college students to grow freely in accordance with the law and only play a corresponding guiding role in the formation of their values and outlook on life. Too loose environment makes col- lege students' free personality grow and ignore the need for ideological and political education. These phenomena are caused by the fact that college students do not change their position. That is, they do not look at the necessity of carrying out ideological and political education in colleges and $\mathrm{u}^{-}$ niversities from an objective perspective. This is also one of the reasons for its lack of external driving force. Also, the social side of college students to receive ideological and political education is also inadequate. With the development of society and the gradual refinement of the social division of labor, the differentiation between various disciplines is becoming more and more detailed. As a new subject, ideological and political education is gradually entering people's vision. The current social situation shows that the existence of ideological and political education has its inevitability. A trade war between China and the United States, behind which the US unilaterally announced controls on Huawei and restricted access to markets, is the most real ideological battle. The western developed countries led by the United States have never given up the consciousness infiltration of our country and tried to infiltrate into colleges and universities and influence the values of college students. It has been reported that an overseas institution buys college students to collect information for them. When college students act as spies under unknown circumstances, regardless of their unconsciousness, they have violated national laws and constitute the crime of divulging state secrets. Various examples show that the social demand for ideological and political education for college students is extremely urgent. Still, because there is a particular barrier between society and school, the social requirements cannot be fully reflected in the school. Therefore, the external driving force of so- $^{-}$ ciety for college students is not significant.

4. 1. 2 Reception Subject Adjustment. In the process of receiving ideological and political education, college students will inevitably encounter obscure theoretical knowledge. If they do not have $\mathrm{e}^{-}$ 
nough willpower and confidence to overcome the problem, they will not be able to integrate the present theoretical knowledge with the theoretical knowledge to be learned. This fully shows the importance of effective internal regulation. Effective internal regulation can be divided into regulating cognition, regulating emotion, regulating will, and so on. First of all, college students' cognitive regulation of themselves is insufficient. Because of the lack of theoretical knowledge and practical experience, college students can more or less realize that the problems in the process of self-reception cannot be effectively adjusted under the premise of understanding the internal and external evaluation. For example, in the face of family changes and natural disasters, and other major trauma, individuals will be immersed in the past, do not want to attend classes, and do not want to receive ideological and political education, which will undoubtedly affect the effectiveness of college students. Secondly, college students lack self-emotional regulation. Because college students are in adolescence, they have a strong sense of self-judgment of the things they come into contact with, so their emotional changes are also significant. In the process of college students receiving ideological and political education, the influence of psychological stereotypes and the appearance of reverse psychology interfere with their reception interest. So they need to adjust themselves emotionally. The drug case of Fudan University is a vivid example. The party concerned is a college student with high education and high intelligence quotient, and the extreme embodiment of the way of dealing with dormitory contradictions is that the self-emotional regulation is not in place. If emotion occupies the upper hand of reason, then tragedy will come. Although the example of this student is a case, it reflects the emotional crisis that countless college students have had. College students' lack of selfemotional regulation is also one of the factors affecting their reception. Thirdly, college students also lack the regulation of self - will. Ideological and political education theory study also belongs to the research and so on. The study will inevitably encounter the obstacle, and some obstacles are relatively small, but some bigger obstacles need firm will to overcome. Under the influence of physiological and psychological characteristics in the $\mathrm{ac}^{-}$ tual learning process, college students' adjustment of self-will is often unsatisfactory. The examples of giving up halfway in the learning process are still common. For example, many college students have encountered the following situations in learning. Once they encounter intricate theoretical knowledge during their study, they cannot help but pick up their mobile phones and divert their attention from the problem. With the consumption of time, the problem is still unsolved and ends with self - comfort. This kind of normality in learning is also a problem encountered by college students in accepting ideological and political education, so the deficiency of college students' selfwill regulation is also one of the reasons that affect the effectiveness of reception.

The external adjustment of the accepting subject mainly refers to the influence of family, school, and society on college students. First of all, the external adjustment of the family to college students is insufficient. During the college period, most college students study in different places and their home location, and their frequency of returning home is less. So the external regulation of the family to college students, especially in the ideological aspects, is becoming less noticeable. Secondly, the external regulation of college students is insufficient. College students tend to talk with their peers rather than the school. Therefore, the relevant departments of the school can only understand the ideological dynamics of college students by indirectly distributing questionnaires and individual conversations. However, the questionnaire distributed in the actual operation cannot cover all aspects of the survey, and college students also have certain randomness in the process of filling out, so the transmission of the 
problem is not generally reactive. The disadvantage of the way of individual conversation is that there is a certain psychological estrangement between the two sides of the conversation, which is caused by the age gap, social status, personal preference, and so on. Taking the campus violence incident of Taiyuan Normal University as an example, the parties did not communicate and negotiate with the school in time to solve the problem, but chose to voice on Weibo and hoped to protect their legitimate rights and interests.

Thirdly, the external regulation of college students is insufficient. The external regulation of college students is mainly realized by public opinion, and the external regulation of college students is uncontrollable, arbitrary, and unclear. Still, take Taiyuan Normal school campus violence as an example, the party surnamed Pan exposed his campus violence incident on Weibo, and another party surnamed Li's Weibo was immediately attacked by a variety of vulgar remarks. What's more, extreme behavior has been made. After the school official statement was issued, the incident continued to ferment, public opinion uproar. On the one hand, the comments on Weibo represent the rejection and antipathy of most netizens to the phenomenon of campus violence, which has a certain positive impact on the shaping of college students' values, which can make them realize the importance of standardizing their own words, deeds and behaviors. For Li, we should adopt the way of enlightenment and guidance to make him realize the anomie of self-behavior rather than the development of the incident towards a worse influence caused by violence and violence, so the external regulation of the society to the college students also affects their reception effect.

4. 1. 3 Reception Subject is Unclear. The direct consequence of college students' unclear cognition of the importance of ideological and political education is vague guidance. The ambiguous orientation can also be understood as the unclear judgment of the direction of college students in the process of reception. The limitation of college students' knowledge and experience makes them unable to correctly understand the importance of ideological and political education and their long - term goals at the present stage. The existing physiological and psychological characteristics of college students determine that the breadth and depth of their thoughts are not enough to make the most appropriate and appropriate cognition of the development direction of ideological and political education. The recipient has and can understand the essence of theory only if it has the corresponding theoretical basis. The lack of guidance of college students in reception is also one of the internal reasons for their weak will. Accepting subjective self - orientation will lead to many negative effects. College students have more freedom and disposable time than junior high school students, which also puts forward higher requirements for doing an $\mathrm{ex}^{-}$ cellent job of time management and planning. The premise of all time management and planning is carried out smoothly is a general goal and a general direction setting. Because of the lack of guidance, college students will have many problems, such as unscientific study and life arrangements, which will lead to their academic malaise.

4. 1. 4 The Subject of Reception is not Selected. College students will face many choices after entering campus life, and they will often encounter embarrassing situations facing many choices. For example, in some campus community recruitment, there will be problems such as how to choose when learning and community activities conflict. For example, in the case of multiple ideas, how to choose the ideas into the self - value system to construct self-stable values, and so on. The university campus is an eclectic garden of thought, where college students can accept all kinds of ideas. Under this situation, many decadent, declining, corrupt and extravagant ideas have also changed their faces. Under the guise of new ideas, they enter the room in a new identity and integrate into the life and study of college students. The 
prevalence of network popular culture is a further example. In the counselors' contest, test questions often appear such a question: a girl inadvertently study, all day indulged in the webcast and think that becoming a network celebrity is one of its life pursuits, and counselors should be persuaded about this situation. As a kind of model culture, the network popular culture is growing with the development of the network broadcast industry and short video economy. Although its existence has certain rationality, it also transmits some money worship, face value, justice, and other ideas to college students. Take this as an example. It is fully explained that under the background of open and inclusive thought, the subject will be impacted by the pluralistic idea. These thoughts will be confused in a new form, which will lead to the unclear choice of college students and affect their reception effect.

4. 1. 5 Absence of Accepting Subject Operation. After receiving ideological and political education, college students lack the knowledge of this aspect, which is related to the excessive reception of theoretical education and the neglect of social practice. In dealing with family relations, especially their relationship with parents, we should use the relevant knowledge of family virtue, filial piety, listening to their advice, caring, and caring for them to deal with family relations. The case of patricide of Peking University students is one of the lack of individual performance of college students. As the proud son of the son of Heaven, Peking University students cannot correctly handle the relationship between them and their mothers, nor do they apply the theoretical knowledge of ideological and political education learned in daily practice, but take an extreme way to deal with it. Finally, the event hurts people and harms them. Although this case is an example, it can still reflect the lack of ideological and political education knowledge. In dealing with the relationship between students, we also need to mobilize the relevant knowledge of ideological and political educa- tion. The occurrence of drug poisoning in Fudan University shows that some college students do not correctly use the relevant knowledge of ideological and political education when dealing with the contradiction between them and their classmates. Their understanding of personal virtue is still lacking. In case of contradiction and conflict, we should be good at finding the principal contradiction and choosing cold treatment or heat treatment method to solve it according to the actual situation. It is necessary to introduce foreign aid in time rather than allow extreme emotions to grow arbitrarily, resulting in an irreversible tragic outcome. In dealing with the relationship between teachers and students, it is also necessary to carry out the relevant knowledge. The suicide incident of $\mathrm{Wu}^{-}$ han Polytechnic students reflects the improper handling of the relationship between teachers and students by college students. When it is contrary to the teacher's opinion, we should find a channel to convey our ideas correctly and not let the bad emotions ferment freely, that is, to find the right contradiction point and change the thinking of solving the problem in time to find the best way to deal with it. Therefore, the lack of reception of the main performance will also affect the effectiveness of reception.

4. 1. 6 Inadequate Processing Capacity of the Recipient. College students are not aware of the processing of ideological and political education theory. The realization of innovation can be $\mathrm{ex}^{-}$ tended to innovation. It must be a two- way combination of theory and practice. College students will encounter various practical problems when they participate in campus cultural activities, and the solution of these problems needs to be realized by the way of thinking of ideological and political education. In the process of practice, the cooperation of team and the efficiency of division of labor cannot be separated from the innovation of team cooperation among college students, and due to the lack of practical experience of college students, the way of dealing with them is more idealized and lack 
of practicality. In the process of learning, college students will encounter learning obstacles. Because of the imperfect theoretical knowledge of college students, some students will fall into self-doubt after losing in trying to overcome, thus giving up the solution to this problem. At the root, the occurrence of this kind of events is caused by the lack of processing ability of the subject, and the subject does not use the way of thinking of ideological and political education to renew his self-concept, and does not use this way of thinking to solve the corresponding contradictions. Thirdly, with the prosperity of the media industry, the opportunities for college students to innovate are gradually increasing. For example, Chen Guo's ideological and political education happiness course, run by college students, is another embodiment of its model innovation. Some college students only use the network media as entertainment tools to form a sharp contrast. Although some college students have some innovative consciousness, their creative ability still needs to be improved compared with the whole group of college students.

\section{2 Factors Influencing the Reception of the Object in Stages of the System}

4. 2. 1 Lack of Acceptance of Object-driven. The object of reception here mainly refers to the teacher. Its internal driving deficiency can be interpreted from its cognition, emotion, will, and so on. First of all, the teacher's internal drive deficiency mainly refers to the teacher's cognition insufficiency. The will is not firm, affected by the teacher's knowledge skill and professional ability. Some teachers are not confident about the role of $i^{-}$ deological and political education, so the transmission from top to bottom has problems. Teachers themselves lack a clear and firm understanding of them, so they more or less question the long term influence of ideological and political education. The function of ideological and political education is present in the future rather than in the present. Its effect is delayed, so it is like a tree, planted in the present and left behind. The cogni- tion of teachers' ideological and political education has a profound influence on the development of their work, so it is of great significance to cultivate high - quality teachers to expand the power of ideological and political education. Secondly, the lack of internal driving force of teachers also includes their emotional factors. Because of the more intelligent and convenient teaching methods, most teachers prefer to use multimedia and other smart devices to teach.

On the one hand, the creation of technical scenarios accelerates the teaching rhythm. On the other hand, it also reduces the emotional communication between teachers and students. The interaction between teachers and students is more and more inclined to the presentation and switching of knowledge. The direct consequence is that teachers regard teaching as a responsibility and obligation rather than a process of emotional exchange and exchange of ideas. Therefore, the lack of internal driving force of teachers affects the effectiveness of college students' reception.

The external drive of accepting objects can be explained from family, school, and society. First of all, most teachers are influenced by the family, on the one hand, the role of teachers, on the other hand, the role of parents, here mainly from its role of parents. After the end of the teaching process, the teacher will return to the family. As a parent, he should take care of the family's daily life and worry about the interpersonal relationship within the family. His energy is more or less dispersed so that students' ideological problems cannot be found and solved in the first place. Second, affected by the school, in addition to teaching tasks, teachers have corresponding scientific research tasks, so the time allocation for ideological and political education will be reduced accordingly. Thirdly, under the influence of society, the demand for teachers in today's society is relatively high. In the process of teaching, they cannot carry out more severe disciplinary measures on students' bodies and minds. Besides, with the progress of 
society and the increasing awareness of people's rights protection, teachers will inevitably take a general attitude towards some situations. The network communication platform's exposure of teachers behavior will become the forefront of public $\mathrm{O}^{-}$ pinion, so to some extent more or less promote their inaction mentality, which has an impact on college students' reception of effectiveness.

4.2. 2 Improper Regulation of Accepting $\mathrm{Ob}^{-}$ ject. The deficiency of accepting object regulation is mainly reflected in the treatment of the teacherstudent relationship. Although teachers have a clear understanding of the relationship between themselves and students, they tend to make a hard adjustment, negative adjustment, and external adjustment. First of all, the receiving object is more inclined to make the hard adjustment and pay attention to the short - term benefits brought by rules and regulations and administrative punishment measures. Still, it neglects the long - term benefits brought by soft control, such as emotional communication and cultural activities. This, although the desired results can be received in the short term, cannot really accept the subject from the internal infection. Secondly, accepting the object is more inclined to external regulation. At the level of ideological and political education, the object of reception focuses on regulating the behavior norms of the external disclosure of the subject to meet the relevant evaluation standards. However, it neglects the importance of guiding and restricting the subject and purifying its inner mind. External regulation cannot fundamentally achieve the ultimate goal of ideological and political education. Only by strengthening internal regulation can the subject realize the norms of external behavior under internal regulation, and can the purpose of ideological and political education be effectively realized. The side of the regulating drive system reflects that the internal control is more effective than the external control. Thirdly, accepting objects tend to negate regulation. In the process of $i^{-}$ deological and political education, accepting ob- jects often use more negative regulation and less positive regulation. Undeniably, the strength of negative regulation is far greater than positive regulation. At present, college students do not have the ability to identify all kinds of events clearly, and the object of reception plays the role of mentor and indexer at this stage. Because different roles and different reception objects have a more obvious effect on behavior correction, the negative control should be used more frequently. With the continuous development of society, it is not difficult to find that negative regulation has a short-term deterrent but cannot establish a closer relationship with the subject of reception, nor can it effectively understand the ideological dynamics of the subject of reception. Therefore, positive regulation is $\mathrm{su}^{-}$ perior to negative regulation in the long run.

4.2. 3 Accept Object Orientation. The unclear orientation of accepting objects is mainly reflected in the lack of guidance of teachers to students. The physiological and psychological characteristics of college students at the present stage determine that they will have more or less reverse psychology in the process of receiving education and then require teachers to guide them correctly. First of all, some teachers' cognition of ideological and political education is still in the primary stage and has not been firmly recognized and persisted, so its top-down guidance is not clear. The negative influence of accepting object - oriented error on ideological and political education is incalculable. The guiding issue is related to the overall development of ideological and political education, and the Party and the state attach great importance to this issue. The Ministry of Education stipulates that teachers of ideological and political education theory should pay special attention to their ideological dynamics and behavior and be responsible for their behavior both inside and outside the classroom. This regulation is a side test of the negative effect caused by the unclear orientation of receiving object. Secondly, teachers and college students have different positions and different social roles, so there are some 
differences in thinking. Therefore, the analysis of the causes of the gap between the ideal state of teaching and the actual state will draw different conclusions. Thirdly, college students have the characteristics of emotional variability and active thinking, and the first choice for college students to ask for help is not a teacher, so teachers cannot grasp the students' thinking dynamics in time. As a result, there is no targeted problem orientation failing to achieve the effect of the right remedy. The unclear orientation of accepting objects well explains the difficulty and difficulty of individual blending ideas under different cognitive fields highlighting the high requirements and strict standards of teachers' profession.

4.2. 4 The Choice of Accepting Object is not Clear. The choice here mainly refers to the teacher' s choice of ways and methods to guide college students to receive education effectively. On the one hand, due to the limitation of practical conditions, teachers' teaching methods are mainly large class teaching, and accepting objects cannot understand the learning state of each student in time, so the individualized teaching scheme has no premise to be implemented. Although this tendency is beneficial to the realization of targeted teaching, it will unconsciously ignore the demands of some students, so the teaching method chosen by accepting the object can only be suitable for some students. That is, it means that it is not universal. On the other hand, the choice of accepting object teaching method will be influenced by subjective factors such as their interests and hobbies, which will make them ignore the demands of students, resulting in their unclear choice, thus affecting the reception effectiveness of college students.

\section{2. 5 Lack of Accepting Object Operation.}

The performance here can be understood as the $\mathrm{a}^{-}$ bility to use deduction as a transfer. On the one hand, teachers are the masters of the classroom and master the power to plan the classroom. Teachers with different subject backgrounds can integrate different subject knowledge into the teaching of ideological and political education or the theory of ideological and political education into the teaching of various subjects. Thus, ideological and political education runs through all kinds of subject education and shows the theory from shallow to deep in different teaching methods. But in real life, this idea of integration has not been transferred to education.

On the other hand, teachers of different disciplines can also participate in discussing the theories and methods of ideological and political education. The sparks of different ways of thinking may jump out of different stars. The development of ideological and political education is not a closed-door process, nor is it a static process such as water, but a process of dynamic development and active reception of beneficial ideas of all parties. Lack of reception of object performance will also affect the reception of college students.

4.2. 6 Lack of Reception of Objects. Processing here can be understood as innovation. The lack of innovation of teachers in the process of ideological, political education and teaching is also one of the reasons that affect the effectiveness of college students. Innovation can be divided into thinking innovation and mode innovation. First of all, teachers in ideological and political education thinking innovation still need to be improved. Thinking innovation includes teaching thinking and management thinking. Some teachers always take the teacher subject theory as the starting point in the actual teaching activities and do not realize the transformation from single subject theory to double subject theory in teaching thinking. In management thinking, some teachers still have simple punitive thought without changing to encouraging thinking. Secondly, teachers still need to improve their way of innovation. Nowadays, in the Internet era, teachers should also integrate into the trend and make full use of the Internet platform to build a new teaching framework, such as using microclass, admiration, and other forms of ideological 
and political education and their learning to guide more college students to love ideological and political education. Therefore, the lack of reception object processing has an impact on the reception effectiveness of college students.

\section{3 Factors Affecting the Reception of the Mediator in a Phased System}

4. 3. 1 Lack of Acceptance Performance. Acceptance medium mainly refers to the carrier of $i^{-}$ deological and political education for college students. At present, the leading carrier is the Internet platform and books. This paper focuses on the discussion from the Internet platform, mainly from two levels, on the one hand, the lack of the use of the intermediary; on the other hand, the lack of the interpretation of the intermediary. The deficiency of the intermediary's use refers to the less form of the special ideological and political education. The few that can be used as the Internet construction platform of ideological and political education in addition to books, even if there is not enough influence. In this era of networking, it is necessary to construct a network platform of ideological and political education with strong influence and pay attention to the diversification of the form of the platform and the popularization of the content, but also in line with the psychological preference and personality characteristics of college students. The deficiency of intermediary deduction refers to the lack of a rich and colorful form of communication platform about ideological and political education. Ideological and political education itself has a particular political color and seriousness, so it will make college students feel alienated from the psychological level to a certain extent. The form of the media is single and rigid, which is not conducive to the development of ideological and political education.

\section{3. 2 Lack of Meso-processing. Reception of} the lack of media processing mainly refers to the form and content of the lack of innovation. The form of intermediary should be innovated in combination with the reception of reality by college students. For example, college students are active in thinking and have the instinct and demand to pursue new things, so the new intermediary can be used as the choice to transmit ideological and political education knowledge. In this process, there must be a cross - fusion of ideas in it. Ideological and political education is a dynamic and open process, so it can be organically combined with all the new, dynamic platforms and will burst out with great vitality. The content innovation of the medium is mainly reflected in the concrete content form of the communication medium. Take shaking sound as an example. Shaking sound as a new media is widely loved by the public. The self media, such as Chen Guo happiness class, also spread the theory of ideological and political education in a different form. This theory of ideological and political education, which appears in story teaching and emotional quotations, is more easily accepted by college students and more recognized by the public. Both the formal innovation of the medium and the content innovation of the medium are human innovation, so the lack of processing of the medium has an impact on the effectiveness of the ideological and political education of college students.

\section{4 Influencing Factors of the Receiving Ring in a Phased System}

4. 4. 1 Interference of Macro - influence Factors such as Politics, Economy, and Society. The macro-environment can be divided into political, economic, social, and cultural aspects. First of all, the international political environment is complicated. Western countries have adopted various strategies to make China suffer enemies in the Asia - Pacific region and provoke political disputes from time to time to start war. The domestic political environment is relatively good. With the development of many corrupt officials and evil forces, the political atmosphere is becoming more and more apparent. Secondly, the international $\mathrm{e}^{-}$ conomic development momentum is good. With the implementation of the Belt and Road initiative, 
the economic development of China and its surrounding countries is accelerating but also hides crises. For example, the unilateral regulation of Huawei by the United States shows that the western countries have not given up the idea of suppressing China. The domestic economy is still strong, and each industry develops well. Thirdly, the social atmosphere is good, but the distance of network environment purification is still far away. Also, cultural diversity also deepens people's belief crisis. Western countries have never given up their ideological penetration of our country and are always ready to put the history of peaceful evolution into practice in China. It can be seen that political, economic, social, and other macro-impact factors are also invisibly interfering with the reception of ideological and political education of college students.

4. 4. 2 The Involvement of Micro - influence Factors such as Family, School, and Community. Micro- environment influencing factors can be discussed from family, school, and community. First of all, from the perspective of the family environment, contemporary parents pay more and more attention to their children's educational situation. However, one - sided attention to their children's intellectual education and neglect of their children's moral education still exists. Parents pay too much attention to their children's cultural achievements but ignore their needs in other development aspects. The direct end is the formation of the whole society in the education of abnormal ideas. For example, educational effectiveness is measured by the single dimension of academic achievement and one - sided pursuit of intellectual development while continually reducing the time to develop other skills. This kind of educational phenomenon reflects that the parents pursue the effect of famous school at the university level and divide the psychology of undergraduate course and specialty artificially, and distinguish the key undergraduate course from the ordinary undergraduate course. With the continuous educational reform progress, these ideas that remain in parents' minds are gradually changing. Secondly, from the point of view of the school environment, the school has always been the leading position to carry out ideological and political education for college students. It is actively taking various forms to improve the effectiveness of ideological and political education. The school environment is relatively good, which is exceptionally suitable for the rapid development of college students' thoughts. Still, it is too loose compared with other environments, and the school is generally the central position of ideological exchange. The blending and contention of multiple $\mathrm{i}^{-}$ deas have almost become the norm here. The crisis behind this overly liberal and liberal atmosphere is a conflict between pluralism and unity. The emergence of this phenomenon also warns schools to pay attention to the erosion of college students by bad ideas in multiple thoughts, so schools should regularly carry out seminars on Marxist theory and call on students to understand its essence deeply. In this way, it can find a fulcrum in the complex kaleidoscope to effectively alleviate the impact of multiple ideas on college students. Besides, all school departments should coordinate and provide corresponding preparations for college students to accept the promotion of practical results. For example, the school's policy - making departments, teaching design departments, educational administration departments, psychological counseling departments, and logistics management departments should coordinate, cooperate with the operation, optimize the school environment and purify students' thoughts. Thirdly, from the point of view of a community environment, although the construction of community moral education has some gain, it has little influence on college students' ideological and political education. The main body of the community is not college students but community residents, so the study of moral education of college students can only be explained in the identity of their community residents. Community ideological and political educa- 
tion mainly refers to self-education, self - management and self - reflection carried out by community residents under the leadership of neighborhood committees. The main forms can be community red song chorus, community self - study Marxism, the selection of community moved characters, and so on. Community education should pay attention to the role of self-education. Only the education that can inspire students to carry out self-education is the reality of education, which is the enlightenment of community education to carry out ideological and political education.

\section{Research on the Countermeasures of Im- proving the Reception Effect of College} Students' Ideological and Political Education from the Perspective of System Theory

\section{1 Driving Regulation System Effectively Defuses Inefficiency of Driving and Regulation}

The driving regulation system provides a new way to solve the problem of power shortage and maladjustment. The operation process of the system is to activate the awakening structure of the brain nerve through psychological elements, thus improving the reception efficiency. Mainly from the mood, will, interest, motivation analysis. ${ }^{[9]}$ First, emotion can be used to activate the brain nerve tissue and then improve the reception efficiency. The emotional experience of college students in receiving ideological and political education is very complex, which is determined by their physiological and psychological characteristics, so the emotions of college students are diverse and changing rapidly. The system takes full advantage of this feature to enhance reception efficiency with emotional stimulation. In the process of reception, first, college students should transform negative emotions into positive emotions and promote reception rate. Second, it emphasizes the essential nature of emotional self - regulation of college students. As the controller of emotion, college students must be good at exploring the method of self-regulating emotion and finding the best outbreak point of emotion for the motive force of emotion to effectively activate the structure of brain nerve awakening and improve the efficiency of reception. Third, college students should be good at identifying emotions, keeping the emotions that can produce motivation, and excreting the $\mathrm{e}^{-}$ motions harmful to the human body. Students in Fudan University involving in the poisoning case were not good at self - regulating extreme emotions. They failed to turn to others in a time when their functions could not regulate their emotions, resulting in tragedy. The importance of accepting the subject's ability to master the ability to regulate emotions is general. Secondly, will power can be used to activate the brain nerve tissue to improve the reception efficiency. Under the influence of their emotional variability, college students are prone to frustration and give up once they encounter obstacles of reception. In view of this issue, the system puts forward the idea of will stimulation to improve reception efficiency. In the process of reception, first, college students should consciously cultivate their own will and improve their persistence in many ways. Second, college students should be good at applying will to the reception of ideological and political education and carrying it out to the end. Third, college students should be free to manipulate their will to become the best tool in accepting activities. College students must walk with the will in receiving education, and the reception of the lack of sense will be broken like a skeleton without the backbone. Will is one of the core elements throughout the reception activity. Thirdly, interest can be used to activate the brain nerve tissue and improve the reception efficiency of the recipient. First, college students should realize where their self - interest is. Second, we should actively cultivate an interest to make its long - term development. Third, we should be good at distinguishing foul taste and high taste and strive to break away from the vulgar taste. Fourth, college students must realize that all interests must be carried out within the limits of law and morality. Interest in any reception ac- 
tivity from development to continuity is, to some extent, one of the key factors determining its direction, that is, the primary level of continuity of the reception activity. If you don't cross the barrier smoothly, the following process, even if it can be carried out, is a mechanical, unintelligible rigid indoctrination process. Therefore, in the initial stage of receiving activities, we should pay close attention to the subtle changes in the subjects' interests and hobbies and give them appropriate guidance. In addition, motivation can be used to activate the brain nerve tissue to improve the reception efficiency of the recipient. First, college students should seriously think about motivation. Second, college students should be able to distinguish between primary motivation and secondary motivation. Third, college students should be good at using motivation and improve their motivation to accept ideological and political education. The subject should consciously switch the material motivation into the spiritual motivation or combine the material motivation with the spiritual motivation and combine the motivation with the goal to realize the linkage between the two. To some extent, this process is also a gradual integration of individual and social needs. In real life, college students can set motivation as a small visible goal. For example, after reading a monograph, you reward yourself with a short title and keep moving forward steadily in self - motivation and self - affirmation.

\section{2 The Guidance Selection System Effectively Dis- entangles the Guidance and the Choice is Unclear}

The guidance selection system provides method guidance for resolving the main body orientation and selecting unknown problems. The following mainly from the guiding selection system elements of the original concept and stereotype psychology, combined with the system's operation to analyze. First of all, the subject should change the original concept and stereotype psychology. The idea that ideological and political education is only floating in the air and has no practical quality to change and look at ideological and political education from a new perspective. The accepting subject must realize that ideological and political education has its rationality. If it fails to appreciate its actual current effect, it can only accept the error of the subject's cognition at the present stage and apply the original value standard to the value judgment. This kind of judgment is groundless, and the only basis is the summary of too hasty pure experience retained in mind, so it is urgent to accept the subject to change the original false thoughts so as to help improve the effectiveness. Secondly, the subject of reception should judge and screen the pluralistic thought accepted by himself and choose the thought which is consistent with the direction of socialist development into the self- cognition system and should be able to identify which thought is beneficial and which thought is useless. The subject of reception must realize that the infiltration of the west into the ideological field of our country has never stopped and these infiltration often moves in the dark in an undetected way. Be alert to accept the subject in the reception of pluralistic ideas to have a choice, sublation to accept. Thirdly, the subject of reception must have a global vision, that is, to look at the problem in a longterm perspective and support it with sufficient knowledge reserve, so that it can effectively resolve the difficult problems with unclear guidance and unclear choice, and then improve the effectiveness of reception. Once the subject has enough views, its logical thinking level will certainly rise to a higher level. The global vision established on this basis will also be more perspective and penetrating. It cannot only find the key to the problem quickly but also see the essence through appearance. As its ability to judge and distinguish right from wrong is gradually enhanced, the influence of its bad thoughts will gradually decrease.

\section{3 Effective Improvement of Operational Perform- ance and Lack of Processing Systems}

The operation process of the operation and processing system is to take knowledge and experience 
as the raw material, and then to take the way of thinking and skills as the tool, to take the information reception and cognitive maintenance of the brain nerve as the carrier, and to stipulate the ability of processing and understanding.

The system provides a solution for effectively improving the problem of lack of operation and insufficient processing, mainly from its constituent elements and the operation process to analyze. First of all, the subject should constantly improve its knowledge and experience reserve. There can be enough theory as support. The subject can always keep a clear mind in the process of receiving ideological and political education, not affected by bad foreign ideas. Once the subject has a clear value judgment and the ability to choose, and then the reception effect can be truly displayed. The continuous expansion of the knowledge and experience reserve of the subject is the inherent requirement of accepting the actual effect. Conversely, if the subject does not have enough theoretical reserves to support it, even if the external conditions are very favorable, it will not help. Secondly, the subject should perfect its thinking and skills of receiving ideological and political education, and continuously explore the best way to accept in order to find the most suitable way to accept himself, so as to achieve twice the result with half the effort. In the process of reception, because of the different individual characteristics of the subject, the appropriate way of reception is also different. Some people tend to accept information audiovisuallya, while others are willing to obtain by inputreading and writing. In a word, the existence of individual differences leads to the difference of the reception mode of the subject, and the reception subject has a certain initiative when selecting the reception mode, so we can draw a conclusion. That is, the best way to accept only the subject has a greater opportunity to find. Thirdly, the receiving subject should pay attention to the correctness of the in- formation reception, and also maintain the original correct cognition about ideological and political education and cannot accept the wrong information.

On the one hand, the subject of reception should have a conscious consciousness of theoretical reception; on the other hand, there should be an instinct to resist the wrong trend of thought, which is also one of the criteria for the reverse test of its validity. In addition, the subject should cultivate his own ability to analyze information to improve the efficiency of understanding the theory of ideological and political education. Reception must be based on understanding, and reception without understanding becomes no source of water and no wood. The basis of understanding is whether it has the ability of complete and connected analysis.

\section{References}

[1] H. R. Yao Si. Reception Aesthetics and Reception Theory [M]. Liaoning: Liaoning United Press,1987.

[2] Gao Jingwen. On Social System Theory and Construction of Harmonious Society Philosophical Studies, 2006(04): 27-33+128.

[3] Liu Gang. Engineering System Theory and Research on Satellite Communication System Related Technology[D]. Beijing Institute of Technology, 1998.

[4] Liu Xianyi. Reception Theory: A New Field[J]. In Educational Research Educational Theory and Practice, 1998(02): 2-7.

[5] Prince Hua. A Study on the Effectiveness of Ideological and Political Education for College Students, Sichuan University, 2007.

[6] Zhang Hongxia. A Study on the Effectiveness of Ideological and Political Education in Colleges and Universities under the Cultural Diversity[D]. Shaanxi Normal University, 2009.

[7] Coleman. Oxford Dictionary of Psychology Shanghai: Shanghai Foreign Language Education Press, 2007.

[8] Suhomlinski, Jiang Liqun. Education and self-education of adolescents[M]. Beijing: Beijing Press, 1984.

[9] Wang Lirong. A Study on the Reception Psychology of Ideological and Political Education, Jilin University, 2009. 